\title{
Optimal Monetary Policy and Transparency under Informational Frictions*
}

\author{
Wataru Tamura ${ }^{\dagger}$
}

May 2013

\begin{abstract}
This paper studies optimal monetary policy and central bank transparency in an economy where firms set prices under informational frictions. The economy is subject to two types of shocks which determine the efficient level of output and the firms' desired mark-up. To minimize the welfare-reducing output gap and price dispersion among the firms, the central bank controls the firms' incentives and expectations by using a monetary instrument and information disclosure about the fundamentals. This paper shows that the optimal policy entails partial disclosure of information and adjustment of the monetary instrument contingent on the disclosed information. Under the optimal policy, the public information is given by a weighted difference of the two shocks so as to induce a negative correlation between those conditional expectations, and monetary policy should offset a detrimental effect of such a disclosure policy on price stabilization.
\end{abstract}

JEL Classification: E31, E52, D83

Keywords: optimal monetary policy, central bank transparency, policy effectiveness, sticky information.

*I am grateful to Masaki Aoyagi, Junichiro Ishida, Shingo Ishiguro, and seminar participants at Meisei University for helpful comments.

${ }^{\dagger}$ Faculty of Economics, The University of Tokyo, 7-3-1, Hongo, Bunkyo-ku, Tokyo, 113-0033 Japan. e-mail: wtamura@e.u-tokyo.ac.jp. 


\section{Introduction}

It is widely recognized that central banks stabilize economy through two channels. ${ }^{1}$ The first is to control market conditions such as money supply and interest rates through its monetary instrument, thereby influencing the private sector's incentives (called the monetary channel). The second is to control market expectations about the macroeconomic fundamentals through public announcements and information disclosure (called the expectations channel). The existing literature has emphasized the importance of managing market expectations to improve the effectiveness of monetary instruments (Woodford (2005)), to reduce excess coordination among firms (Morris and Shin (2002)), and to establish reputations and increase the credibility of monetary policy (Faust and Svensson (2001)). Despite the recent advances, however, little is known about the optimal policy in the general policy space over both channels.

The aim of this paper is to characterize the optimal policy when the central bank uses both channels. Specifically, the central bank chooses an instrument rule and a disclosure rule which determine nominal demand and public information for each realization of the fundamentals. By making its monetary instrument contingent on the realization of shocks, the central bank can reduce welfare losses due to fluctuations of the fundamentals. As pointed out by Baeriswyl and Cornand (2010), however, the central bank's monetary instrument may signal its private information to the private sector and cause undesirable volatility of prices. Thus, the market expectations reflect not only by the disclosed information but also by the implicit signals that accompany the adjustment of its monetary instrument.

The model economy presented in this paper is a standard rational expectations model with flexible prices developed in Adam (2007). The economy is subject to two types of shocks: the labor supply shock induces variations in the efficient level of output and the mark-up shock (a shock to product market competition) induces variations in firms' desired mark-up. Monopolistically competitive firms have incentives to accommodate these shocks as well as the nominal demand controlled by the central bank. While prices are flexible, monetary policy may be non-neutral due to informational frictions. In the present model, informational frictions stem from the existence of three types of firms that differ in their information capabilities. Fully informed firms observe both

\footnotetext{
${ }^{1}$ For surveys on recent discussion about central bank transparency in monetary policy, see Geraats (2002) and Blinder et al. (2008).
} 
the fundamentals and the policy outcomes; partially informed firms observe the policy outcomes but not the fundamentals; and uninformed firms observe neither. This specification clarifies the role of each channel: the monetary channel affects the incentives of the fully and partially informed firms and the expectations channel affects the belief of the partially informed firms about the fundamentals.

To understand how the expectations channel works in the present model, let us discuss how the partially informed firms respond to information about the two shocks. First, a negative shock to labor supply increases the output gap when nominal demand remains constant. Second, a positive mark-up shock increases the desired mark-up. ${ }^{2}$ Therefore, the firms raise prices when the public information indicates a negative labor supply shock or a positive mark-up shock. By choosing a disclosure rule, the central bank induces a distribution of the expectations formed by the partially informed firms. In particular, there are two ways to control variability of the prices set by the partially informed firms. The first is to adjust the precision of information revealed to them. Intuitively, as public information becomes less precise, they become less responsive to the information. The second is to disclose partial information about the shock so that they cannot distinguish a negative shock to labor supply and a negative shock to the mark-up. As such, the central bank can prevent them from adapting to each shock, thereby stabilizing their prices.

The optimal policy involving both monetary and expectations channels is implemented as follows. First, the central bank creates an index as a linear combination of the two shocks. It then publicly discloses it and chooses the monetary instrument contingent only on that index. The index should be constructed so that the partially informed firms cannot distinguish a negative shock to labor supply and a positive mark-up shock. In other words, the optimal policy induces a negative correlation the expectation of the labor supply shock and that of the mark-up shock. From the above discussion, such a disclosure policy appears to magnify price volatility and hence reduce social welfare.

The first key to understanding the optimal policy is the indirect effect of public information through strategic interactions. Note that the disclosed information affects the expectations of the partially informed firms but not those of the fully informed firms. However, the information indirectly affects the incentives of the fully informed firms through adjustment in behavior by the

\footnotetext{
${ }^{2}$ It can be interpreted as a negative shock to product market competition.
} 
partially informed firms to the public information. By exploiting strategic complementarities in pricing decisions, the central bank can reduce price dispersion caused by the fully informed firms through partial disclosure.

Flexibility of the monetary instrument provides another key. By adjusting nominal demand contingent on the disclosed information, the central bank can offset the detrimental effect of partial disclosure. Thus, the expectations channel is directed at reducing volatility of prices that cannot be neutralize through the monetary channel. Under the optimal policy, the two channels complement each other.

To further examine the role of the monetary instrument, this paper also characterizes the optimal disclosure rule when nominal demand is fixed at a certain level (called the inflexible instrument). Without the flexible monetary instrument, it is shown that the central bank needs to place more weight on controlling the belief of the partially informed firms.

This paper contributes to the literature on central bank transparency. As noted above, this paper is the first to present the optimal transparency policy in the general policy space. ${ }^{3}$ In the growing debate on the social value of public information, started by Morris and Shin (2002), most papers focus on the optimal precision of public information about the one dimensional state variable (e.g., Hellwig (2005), Morris and Shin (2007), Cornand and Heinemann (2008)). In contrast, the present paper examines how to control information about the multidimensional state variables. To induce coordination among firms, the optimal disclosure rule in the present paper controls the informational content of the public information by mixing the state variables rather than by mixing noises.

This paper also contributes to the literature on optimal monetary policy under informational frictions. Although informational frictions may stem from different sources, the literature mostly focuses on the case where each agent receives idiosyncratic information about the policy instrument or the fundamentals (e.g., Adam (2007), Baeriswyl and Cornand (2010), and Lorenzoni (2010)). Recently, Angeletos and La'O (2012) investigate the optimal monetary policy under informational frictions based on the primal approach. In a related paper, Baeriswyl and Cornand (2010) examine

\footnotetext{
${ }^{3}$ Recently, Kamenica and Gentzkow (2011) and Tamura (2012) analyze optimal information structure in a senderreceiver game.

${ }^{4}$ For example, Lucas (1972)'s island model, Mankiw and Reis (2002)'s sticky information model, and Sims (2003)'s rational inattention model provide microfoundations of informational frictions.
} 
how the signaling effect of the choice of the monetary instrument distorts policy responses to shocks under three transparency regimes; transparent, opaque, and intermediate. ${ }^{5}$ Unlike their paper, the present paper provides an analytical solution to the optimal monetary policy that fully internalizes its signaling effects.

The rest of the paper is organized as follows. Section 2 presents the model economy. Section 3 analyzes firms' incentives and characterizes the equilibrium pricing strategies. Section 4 reformulates the problem and characterizes the optimal policy. Section 5 examines the optimal transparency policy under the inflexible instrument. Section 6 concludes the paper with discussions about possible extensions.

\section{The model economy}

An economy is populated by a representative household, a continuum of monopolistically competitive firms, and a central bank, and is subject to two types of shocks: a labor supply shock $y^{*}$ which determines the efficient output level and a mark-up shock (or real demand shock) $u$ which affects firms' desired mark-up. Nominal demand $q$ is determined by the monetary instrument.

\subsection{Firms}

The pricing rule of firm $i$ under monopolistic competition is given by

$$
p_{i}=\mathbb{E}_{i}\left[p+\xi\left(y-y^{*}\right)+u\right]
$$

where the lower-case letters indicate a percentage deviation from the equilibrium under no uncertainty. ${ }^{6}$ The pricing rule in (1) depends on the expected values of (i) the aggregate price $p=\int p_{j} d j$, (ii) the real output gap $y-y^{*}$ where $y=\int y_{j} d j$, and (iii) the mark-up shock $u$. The parameter $\xi>0$ determines the sensitivity of the optimal price to the output-gap. Since the nominal aggregate

\footnotetext{
${ }^{5}$ In their paper, transparency means full disclosure; opacity means no disclosure and the monetary instrument with no signaling effects; and intermediate transparency means no disclosure and the monetary instrument with signaling effects.

${ }^{6}$ Adam (2007) provides the microfounded derivation.
} 
demand $q$ is expressed as $q=y+p$, the firm's pricing rule is rewritten as

$$
p_{i}=\mathbb{E}_{i}\left[(1-\xi) p+\xi q-\xi y^{*}+u\right]
$$

Throughout this paper, prices are assumed to be strategic complements, i.e., $0<\xi \leq 1$.

The labor supply shock $y^{*} \sim N\left(0, \sigma_{y^{*}}^{2}\right)$ and the mark-up shock $u \sim N\left(0, \sigma_{u}^{2}\right)$ are assumed to be Gaussian. For simplicity, suppose that $\operatorname{cov}\left(y^{*}, u\right)=0$. Let $\Sigma$ be the variance-covariance matrix of $\left(y^{*}, u\right)$

\subsection{The central bank}

The central bank maximizes the expected utility of the representative household by adjusting nominal demand and disclosing information. As shown in Adam (2007), ${ }^{7}$ maximizing the second order approximation of the welfare of the representative household is equivalent to minimizing the unconditional expectation of the following loss function

$$
L=\left(y-y^{*}\right)^{2}+\frac{\bar{\theta}}{\bar{\xi}} \int_{0}^{1}\left(p_{j}-p\right)^{2} d j
$$

where $\bar{\theta}$ is the average value of the price elasticity of demand. The welfare loss comes from output gap and price dispersion.

A policy $(f, g)$ consists of an instrument rule $f: \mathbb{R}^{2} \rightarrow \mathbb{R}$ and a disclosure rule $g: \mathbb{R}^{2} \rightarrow M$, which specify the monetary instrument $q=f\left(y^{*}, u\right) \in \mathbb{R}$ and the public information $m=g\left(y^{*}, u\right) \in$ $M$ for each realization of $\left(y^{*}, u\right)$. Note that one can extend the policy space to allow randomization, but it does not affect any results of this paper. ${ }^{8}$ A pair $(q, m)$ is the policy outcomes.

\subsection{Information structure}

Following Mankiw and Reis (2002), this paper assumes that information diffuses slowly through the economy. To express this, suppose that, while the central bank perfectly observes $\left(y^{*}, u\right)$, the

\footnotetext{
${ }^{7}$ See Appendix A.2. Equation (66) in his paper.

${ }^{8} \mathrm{~A}$ (generalized) policy $\sigma: \mathbb{R}^{2} \rightarrow \Delta(\mathbb{R} \times M)$ specifies a joint distribution $g\left(\cdot \mid y^{*}, u\right) \in \Delta(\mathbb{R} \times M)$ of $(q, m) \in \mathbb{R} \times M$ for each realization of $\left(y^{*}, u\right)$.
} 
firms are divided into three types depending on their information capabilities. ${ }^{9}$ A fully informed firm observes the fundamentals $\left(y^{*}, u\right)$ and the policy outcomes $(q, m)$. A partially informed firm observes only $(q, m)$. An uninformed firm observes neither $\left(y^{*}, u\right)$ nor $(q, m)$. Let $a_{f} \in[0,1]$ denote the fraction of the fully informed firms. Similarly, $\alpha_{p} \in[0,1]$ the fraction of the partially informed firms, and $\alpha_{u} \in[0,1]$ the fraction of the uninformed firms. Note that $\alpha_{f}+\alpha_{p}+\alpha_{u}=1$. Parameter $\alpha_{f}$ captures information stickiness in the spirit of the original work of Mankiw and Reis (2002) while $\alpha_{u}$ may be interpreted as inattentiveness to public information.

The specification of informational frictions in this paper has several advantages. First, it allows us to obtain equilibrium pricing under any arbitrary policy.Second, it highlights the roles of the monetary and expectations channels. The monetary channel affects the incentives of the fully informed and partially informed firms while the expectations channel affects the posterior belief of the partially informed firms. ${ }^{10}$

Let us introduce some notations: $\hat{y}^{*} \equiv \mathbb{E}\left[y^{*} \mid q, m\right]$ denotes the conditional expectation given the policy outcomes $(q, m)$, and $\Delta_{y^{*}} \equiv y^{*}-\hat{y}^{*}$ the residual. Other variables, $\hat{u}$ and $\Delta_{u}$, are analogously defined.

\subsection{Timing of events}

The sequence of events is as follows. First, the central bank publicly chooses its policy $(f, g)$. Second, the nature draws the labor supply shock $y^{*}$ and the mark-up shock $u$. Third, the central bank observes $\left(y^{*}, u\right)$ and chooses monetary instrument $q=f\left(y^{*}, u\right)$ and public information $m=$ $g\left(y^{*}, u\right)$. Finally, firms simultaneously set their prices: fully informed firms condition their choices on $\left(y^{*}, u\right)$ and $(q, m)$; partially informed firms on $(q, m)$; and uninformed firms only on their prior.

\section{$3 \quad$ Equilibrium pricing}

This section derives firms' pricing strategies in equilibrium. To understand the basic working of the model, Subsection 3.1 examines the incentives of each type of firms. Next, Subsection 3.2 characterizes pricing strategies in equilibrium and an aggregate price level as a function of the

\footnotetext{
${ }^{9}$ As discussed in concluding remarks, it can be extended to the case where the central bank observes imperfect signals about the fundamentals.

${ }^{10}$ As seen below, monetary neutrality holds if $a l p a h_{u}=0$ and information disclosure is ineffective if $\alpha_{p}=0$.
} 
market expectations about the fundamentals. Throughout this section, a policy $(f, g)$ is fixed.

\subsection{Firms' incentives}

\subsubsection{Fully informed firms}

First, the incentives of fully informed firms are analyzed. Any such firm knows what other firms know, so its expectation about the aggregate price level must be consistent with its realization. Therefore the pricing rule (2) is expressed as

$$
p_{f}=(1-\xi) p+\xi q-\xi y^{*}+u
$$

As a benchmark, consider the case of $\alpha_{f}=1$. In the symmetric equilibrium $p_{f}=p$, it follows from pricing rule (3) that

$$
\left(y-y^{*}\right)=-\frac{u}{\xi}
$$

Notice that output gap and price dispersion are determined independent of the policy. In other words, the central bank has no power to influence the real economy when all firms are fully informed. Welfare loss arises from firms responses to the mark-up shock.

\subsubsection{Partially informed firms}

Each partially informed firm $i \in I_{p}$ observes only the realization of $(q, m)$, and then forms conditional expectations of $y^{*}, u$ and $p$. Pricing rule (2) is expressed as

$$
p_{p}=(1-\xi) \hat{p}+\xi q-\xi \hat{y}^{*}+\hat{u}
$$

As in the previous benchmark, consider the case of $\alpha_{p}=1$. In the symmetric equilibrium $p_{p}=p$, the output gap is given by

$$
\left(y-y^{*}\right)=-\frac{\hat{u}}{\xi}-\left(y^{*}-\hat{y}^{*}\right)
$$

Again the monetary channel is ineffective. The expectations channel is, however, effective. Output 
gap depends on the conditional expectations of the fundamentals, and hence the central bank can reduce losses by controlling information available to the partially informed firms. When the central bank chooses full disclosure $g\left(y^{*}, u\right)=\left(y^{*}, u\right)$, which induces $\hat{y}^{*}=y^{*}$ and $\hat{u}=u$ for every $\left(y^{*}, u\right)$, the expected loss is given by $\operatorname{var}(u) / \xi^{2}$, which coincides with the first benchmark case. Under a disclosure rule $g\left(y^{*}, u\right)=y^{*}$, which induces $y^{*}=y^{*}$ and $\hat{u}=\mathbb{E}[u]=0$ for every $\left(y^{*}, u\right)$, the central bank can achieve the first-best outcome (i.e., zero welfare loss).

\subsubsection{Uninformed firms}

Each uninformed firm $i \in I_{u}$ chooses its price so that

$$
p_{u}=(1-\xi) \mathbb{E}[p]+\xi \mathbb{E}[q]-\xi \mathbb{E}\left[y^{*}\right]+\mathbb{E}[u]
$$

When $\alpha_{u}=1$, the symmetric equilibrium $p_{u}=p$ implies

$$
y=q-\mathbb{E}[q] .
$$

Hence by choosing an instrument rule $f\left(y^{*}, u\right)=y^{*}$, the central bank achieves the first-best outcome. Note that monetary policy is non-neutral as Lucas (1972) pointed out, while the disclosure rule has (trivially) no effects.

\subsection{Equilibrium}

From (3) - (5) with $p=\alpha_{f} p_{f}+\alpha_{p} p_{p}+\alpha_{u} p_{u}$, a Bayesian Nash equilibrium is characterized as follows.

Lemma 1 Pricing strategies and aggregate price level in equilibrium are as follows

$$
\begin{aligned}
p_{u} & =\bar{q} \\
p_{p} & =p_{u}+\frac{\lambda}{1-\alpha_{u}}\left((q-\bar{q})-\hat{y}^{*}+\frac{1}{\xi} \hat{u}\right) \\
p_{f} & =p_{p}+\frac{\kappa}{\alpha_{f}}\left(-\Delta_{y^{*}}+\frac{1}{\xi} \Delta_{u}\right) \\
p & =\bar{q}+\lambda\left((q-\bar{q})-\hat{y}^{*}+\frac{1}{\xi} \hat{u}\right)+\kappa\left(-\Delta_{y^{*}}+\frac{1}{\xi} \Delta_{u}\right)
\end{aligned}
$$


where $\lambda=\frac{\left(1-\alpha_{u}\right) \xi}{\left(1-\alpha_{u}\right) \xi+\alpha_{u}}$ and $\kappa=\frac{\alpha_{f} \xi}{\alpha_{f} \xi+\left(1-\alpha_{f}\right)}$.

The aggregate price level depends on the nominal demand $q$ and the market expectations $\hat{y}^{*}$ and $\hat{u}$ which are observed by both fully and partially informed firms, and also on the residuals $\Delta_{y^{*}}$ and $\Delta_{u}$ which are observed only by the fully informed firms. Two parameters $\lambda$ and $\kappa$ measure the sensitivities of the aggregate price level to these factors. Note that $\lambda, \kappa \in[0,1]$ and that $\lambda \geq \kappa$.

Similarly, variability of the equilibrium prices depend on the distribution of types $\left(\alpha_{u}: \alpha_{p}: \alpha_{f}\right)$ and the degree of strategic complementarity $(0 \leq 1-\xi<1)$. The price of the partially informed firm becomes more volatile as $\alpha_{u}$ decreases. ${ }^{11}$ Similarly, volatility of $\left(p_{f}-p_{p}\right)$, which is induced by the variability of the residuals, is increasing with $\alpha_{f}$. Intuitively, as more firms respond to the monetary instrument and to the fundamentals, firms have strong incentives to respond to them due to strategic complementarities. ${ }^{12}$

Several remarks should be made about monetary (non-)neutrality. First, an increase in $\bar{q}$ affects neither the expected output gap nor the degree of price dispersion since it is exactly canceled out by an increase in prices. So it can be assumed that $\bar{q}=0$, without loss of generality. Second, monetary neutrality holds if there is no uninformed firms $\left(\alpha_{u}=0\right)$. In this case, $\lambda=1$, so an increase in $q$ by one unit results in an increase in $p_{f}$ and $p_{p}$ (and hence $p$ when $\alpha_{u}=0$ ) by one unit. Conversely, the monetary instrument is non-neutral and affects real economy whenever there are uninformed firms.

\subsection{Welfare loss in equilibrium}

Under equilibrium pricing (6)-(9), the output gap volatility is written as

$$
\mathbb{E}\left(y-y^{*}\right)^{2}=\mathbb{E}\left((1-\lambda)\left(q-\hat{y}^{*}\right)-\lambda \frac{\hat{u}}{\xi}\right)^{2}+\mathbb{E}\left((1-\kappa) \Delta_{y^{*}}+\kappa \frac{\Delta_{u}}{\xi}\right)^{2}
$$

Note that no disclosure induces $\hat{y}^{*}=\hat{u}=0$ while full disclosure induces $\Delta_{y^{*}}=\Delta_{u}=0$.

Similarly, the unconditional expectation of price dispersion is written as

$$
\mathbb{E}\left[\int_{0}^{1}\left(p_{j}-p\right) d j\right]=\alpha_{u}\left(1-\alpha_{u}\right) \mathbb{E}\left(p_{p}-p_{u}\right)^{2}+\alpha_{f}\left(1-\alpha_{f}\right) \mathbb{E}\left(p_{f}-p_{p}\right)^{2}
$$

\footnotetext{
${ }^{11}$ Note that coefficient in $(7), \lambda /\left(1-\alpha_{u}\right)=\xi /\left(\left(1-\alpha_{u}\right) \xi+\alpha_{u}\right)$, is decreasing in $\alpha_{u}$.

${ }^{12}$ Indeed, $\lambda$ and $\kappa$ are increasing with $\xi$.
} 
Thus, the central bank should reduce volatility of $\left(p_{p}-p_{u}\right)$, which is induced by the fluctuations of the conditional expectations, as well as that of $\left(p_{f}-p_{p}\right)$, which is induced by the fluctuations of the residuals. Note that $\mathbb{E}\left(p_{p}-p_{u}\right)^{2}$ is minimized under no disclosure while $\mathbb{E}\left(p_{f}-p_{p}\right)$ is minimized under full disclosure.

\section{Optimal policy}

The central bank's problem is formulated as follows.

$$
\begin{aligned}
& \min _{(f, g)} \mathbb{E}\left[\left(y-y^{*}\right)^{2}+\frac{\bar{\theta}}{\xi} \int_{0}^{1}\left(p_{j}-p\right)^{2} d j\right] \\
& \text { s.t. } \quad(6)-(9) \text { and } y=q-p .
\end{aligned}
$$

In general, the first-order approach in the standard optimal control problem cannot be applied since the optimal instrument rule must internalize its signaling effects. That is, what information is revealed through the monetary instrument is determined by the entire policy and not by its local conditions. By virtue of the generality of disclosure rules, however, the choice of an instrument rule can be restricted to the class of functions that depend only on the public information $m$.

Lemma 2 In the set of optimal policies, if nonempty, there exists a policy $(f, g)$ such that the instrument rule $f$ can be written as a function of the public information $m=g\left(y^{*}, u\right)$ (i.e., $f\left(y^{*}, u\right)=h\left(g\left(y^{*}, u\right)\right)$ for some $\left.h: M \rightarrow \mathbb{R}\right)$.

Intuitively, the optimal instrument rule can be designed so as to influence the economy only through the monetary channel. Formally, for any policy $(f, g)$, there is a policy $(\tilde{f}, \tilde{g})$ such that $\tilde{g}$ reveals the same information $\tilde{m}=(q, m)$ revealed under $(f, g)$, and $\tilde{f}$ specifies the same level of nominal demand $q$ as $g$ chooses. ${ }^{13}$ Obviously, $(\tilde{f}, \tilde{g})$ induces the same outcome for each realization of the fundamentals but $\tilde{f}$ has no signaling effects in the sense that it reveals no additional information about the fundamentals. Hence, the optimal policy can be represented by a pair $(g, h)$ where $g: \mathbb{R}^{2} \rightarrow M$ is a disclosure rule and $h: M \rightarrow \mathbb{R}$ is an instrument rule.

\footnotetext{
${ }^{13}$ Fix a policy $(f, g)$. Now consider a policy $\tilde{f}: \mathbb{R}^{2} \rightarrow \mathbb{R}$ and $\tilde{g}: \mathbb{R}^{2} \rightarrow \tilde{M}$ with $\tilde{M}=\mathbb{R} \times M$ such that $\tilde{f}\left(y^{*}, u\right)=f\left(y^{*}, u\right)$ and $\tilde{g}\left(y^{*}, u\right)=\left(f\left(y^{*}, u\right), g\left(y^{*}, u\right)\right) \in \tilde{M}$. Then the instrument rule $\tilde{f}$ can be written as a function of $\tilde{m}=\tilde{g}\left(y^{*}, u\right)$. That is, $\tilde{f}=h \circ \tilde{g}$ where $h(q, m)=q$.
} 
In Subsection 4.1, the optimal instrument rule $h: M \rightarrow \mathbb{R}$ given an arbitrary disclosure rule $g$ will be characterized. In Subsection 4.2, the "indirect" loss function, which is a function of the disclosure rule, is derived and then the optimal disclosure rule is obtained.

\subsection{Optimal instrument rule}

Fix a disclosure rule. From Lemma 2, this section addresses the optimal instrument rule $h$ : $M \rightarrow \mathbb{R}$. The optimal instrument rule solves the following problem for each realization of $m$.

$$
\begin{aligned}
& \min _{q} \mathbb{E}\left[\left(y-y^{*}\right)^{2}+\frac{\bar{\theta}}{\xi} \int_{0}^{1}\left(p_{j}-p\right)^{2} d j \mid m\right] \\
& \text { s.t. }(6)-(9) \text { and } y=q-p .
\end{aligned}
$$

From (11) and (10), the above problem is equivalent to

$$
\min _{q}\left((1-\lambda)\left(q-\hat{y}^{*}\right)-\lambda \frac{\hat{u}}{\xi}\right)^{2}+\frac{\bar{\theta}}{\bar{\xi}} \frac{\alpha_{u} \lambda^{2}}{1-\alpha_{u}}\left(q-\hat{y}^{*}+\frac{\hat{u}}{\bar{\xi}}\right)^{2}
$$

Since the problem is concave, the first-oder condition fully characterizes the optimal instrument rule..$^{14}$

Proposition 1 Under the optimal instrument rule, nominal demand is determined to satisfy

$$
q=\hat{y}^{*}-\gamma \frac{\hat{u}}{\xi}
$$

where $\gamma \equiv \frac{(\bar{\theta}-1) \lambda}{(\bar{\theta}-1) \lambda+1}$

Given a disclosure rule, welfare loss comes from volatility of the conditional expectations $\left(\hat{y}^{*}, \hat{u}\right)$ and the residuals $\left(\Delta_{y^{*}}, \Delta_{u}\right)$. The optimal instrument rule should minimize welfare losses due to $\left(\hat{y}^{*}, \hat{u}\right)$. When nominal demand satisfies $(12)$, the "indirect" loss function is given by

$$
\begin{aligned}
L= & \frac{\bar{\theta} \xi\left(1-\alpha_{u}\right)}{\bar{\theta} \xi\left(1-\alpha_{u}\right)+\alpha_{u}}\left(\frac{\hat{u}}{\xi}\right)^{2}+\frac{\bar{\theta} \xi \alpha_{f}}{\bar{\theta} \xi \alpha_{f}+1-\alpha_{f}}\left(\frac{\Delta_{u}}{\xi}\right)^{2} \\
& +\frac{1-\alpha_{f}}{\bar{\theta} \xi \alpha_{f}+1-\alpha_{f}}\left(\frac{\left(\bar{\theta} \xi \alpha_{f}+1-\alpha_{f}\right) \Delta_{y^{*}}-(\bar{\theta}-1) \xi \alpha_{f} \xi^{-1} \Delta_{u}}{\xi \alpha_{f}+1-\alpha_{f}}\right)^{2}+\text { t.i.p. }
\end{aligned}
$$

\footnotetext{
${ }^{14}$ If $\lambda=1$, or equivalently, if $\alpha_{u}=0$, then any levels of $q$ lead the same welfare loss. That is, monetary neutrality holds when there are no uninformed firms.
} 
where t.i.p. is such that $\mathbb{E}($ t.i.p. $)=0$ for any disclosure rule. Notice that by choosing a disclosure rule, the central bank controls the joint distribution of $\left(\hat{u}, \Delta_{y^{*}}, \Delta_{u}\right)$.

It may be useful to consider benchmark cases before presenting the optimal disclosure rule. When $\alpha_{f}=0$, the indirect loss function is

$$
L=\frac{\bar{\theta} \xi\left(1-\alpha_{u}\right)}{\bar{\theta} \xi\left(1-\alpha_{u}\right)+\alpha_{u}}\left(\frac{\hat{u}}{\bar{\xi}}\right)^{2}+\Delta_{y^{*}}^{2}+t . i . p .
$$

By choosing $g\left(y^{*}, u\right)=y^{*}$, the central bank can achieve the first-best. On the other hand, when $\alpha_{f}>0$, the first-best requires $\hat{u}^{2}=0$ and $\Delta_{u}^{2}=0$ almost surely, which is obviously impossible unless $\sigma_{u}^{2}=0$.

When $\alpha_{p}=0$ (or equivalently, $\alpha_{f}=1-\alpha_{u}$ ), the central bank need not account signaling effects of the monetary instrument. Therefore, the optimal monetary policy can be conducted under full

disclosure. Thus, the unconditional expected loss is $\mathbb{E} L=\frac{\bar{\theta} \xi \alpha_{f}}{\theta \xi \alpha_{f}+1-\alpha_{f}}\left(\frac{\operatorname{var}(u)}{\xi^{2}}\right)$, which coincides with Baeriswyl and Cornand's (2010) benchmark case.

\subsection{Optimal disclosure rule}

Let us now return to the original problem. Note that by the law of iterated expectations, the variances and the covariance of the residuals are written as follows: $\mathbb{E}\left[\Delta_{y^{*}}^{2}\right]=\mathbb{E}\left[\left(y^{*}-\hat{y}^{*}\right)^{2}\right]=$ $\mathbb{E}\left[y^{*}\right]-\mathbb{E}\left[\left(\hat{y}^{*}\right)^{2}\right], \mathbb{E}\left[\Delta_{y^{*}} \Delta_{u}\right]=\mathbb{E}\left[y^{*} u\right]-\mathbb{E}\left[\hat{y}^{*} \hat{u}\right]$, and $\mathbb{E}\left[\Delta_{u}^{2}\right]=\mathbb{E}\left[u^{2}\right]-\mathbb{E}\left[\hat{u}^{2}\right]$. Then the unconditional expected loss function is expressed as

$$
\mathbb{E} L=-\mathbb{E} \Phi\left(\hat{y}^{*}, \hat{u}\right)+\widehat{t . i . p}
$$

where $\Phi\left(\hat{y}^{*}, \hat{u}\right)$ is a quadratic function given below and $\widehat{t . i . p}$. denotes terms that are independent of policy:

$$
\begin{aligned}
\Phi\left(\hat{y}^{*}, \hat{u}\right)= & -\left[\frac{\bar{\theta} \xi\left(1-\alpha_{u}\right)}{\bar{\theta} \xi\left(1-\alpha_{u}\right)+\alpha_{u}}-\frac{\bar{\theta} \xi \alpha_{f}}{\bar{\theta} \xi \alpha_{f}+1-\alpha_{f}}\right]\left(\frac{\hat{u}}{\bar{\xi}}\right)^{2} \\
& +\frac{1-\alpha_{f}}{\bar{\theta} \xi \alpha_{f}+1-\alpha_{f}}\left(\frac{\left(\bar{\theta} \xi \alpha_{f}+1-\alpha_{f}\right) \hat{y}^{*}-(\bar{\theta}-1) \xi \alpha_{f} \xi^{-1} \hat{u}}{\xi \alpha_{f}+1-\alpha_{f}}\right)^{2} .
\end{aligned}
$$


Hence, the optimal disclosure rule is the solution to $\max _{g} \mathbb{E} \Phi\left(\hat{y}^{*}, \hat{u}\right) \cdot{ }^{15}$

Let $H$ be the Hessian matrix of $\Phi$. It can be shown that $H$ has a unique positive eigenvalue. From Tamura (2012) follows the next proposition.

Proposition 2 If $y^{*}$ and $u$ are normally distributed, then the optimal disclosure rule is such that

$$
g\left(y^{*}, u\right)=b_{y^{*}} \sigma_{y^{*}}^{-1} y^{*}+b_{u} \sigma_{u}^{-1} u
$$

where $\left(b_{y^{*}}, b_{u}\right)$ is the eigenvector associated with the unique positive eigenvalue of $\Sigma^{\frac{1}{2}} H \Sigma^{\frac{1}{2}} \cdot{ }^{16}$

\subsection{Discussion}

The optimal policy is implemented as follows. First, the central bank publicly discloses a policy index $m=b_{y^{*}} \sigma_{y^{*}}^{-1} y^{*}+b_{u} \sigma_{u}^{-1} u$, which is a linear combination of the two shocks. Second, it controls nominal demand contingent on the policy index so that $q=\beta m$ where $\beta=\sigma_{y^{*}} b_{y^{*}}-\gamma \sigma_{u} b_{u} / \xi{ }^{17}$

Figure 1a illustrates how the fraction of the fully informed firms affects the second moments of the estimates induced by the optimal disclosure rule. Since $m$ is a linear combination of $\left(y^{*}, u\right)$, the variances of $\hat{y}^{*}$ and $\hat{u}$ satisfy the following property:

$$
\frac{\operatorname{var}\left(\hat{y}^{*}\right)}{\operatorname{var}\left(y^{*}\right)}+\frac{\operatorname{var}(\hat{u})}{\operatorname{var}(u)}=1
$$

As $\alpha_{p}$ decreases and $\alpha_{f}$ increases, it becomes less important to withhold information about $u$. This effects lead to the monotonic change in $\operatorname{var}\left(\hat{y}^{*}\right)$ and $\operatorname{var}(\hat{u})$.

\footnotetext{
${ }^{15}$ Explicitly, $\widehat{\text { t.i.p. }}$ is given by

$$
\widehat{t . i . p .}=\frac{\bar{\theta} \xi \alpha_{f}}{\bar{\theta} \xi \alpha_{f}+1-\alpha_{f}}\left(\frac{u}{\xi}\right)^{2}+\frac{1-\alpha_{f}}{\bar{\theta} \xi \alpha_{f}+1-\alpha_{f}}\left(\frac{\left(\bar{\theta} \xi \alpha_{f}+1-\alpha_{f}\right) y^{*}-(\bar{\theta}-1) \xi \alpha_{f} \xi^{-1} u}{\xi \alpha_{f}+1-\alpha_{f}}\right)^{2}
$$

${ }^{16}$ The eigenvector $\left(b_{y^{*}}, b_{u}\right)$ satisfies

$$
\frac{b_{y^{*}}}{b_{u}}=\frac{\left(\sigma_{y^{*}}^{2} H_{11}-\sigma_{u}^{2} H_{22}\right)+\sqrt{\left(\sigma_{y^{*}}^{2} H_{11}-\sigma_{u}^{2} H_{22}\right)^{2}+4 \sigma_{y^{*}}^{2} \sigma_{u}^{2} H_{12}^{2}}}{2 \sigma_{y^{*}} \sigma_{u} H_{12}} .
$$

${ }^{17}$ Since $m$ is a linear combination of the two shocks, $\left(y^{*}, u, m\right)$ are normally distributed. Therefore, the conditional expectation is given by

$$
\mathbb{E}\left[\left(\begin{array}{c}
y^{*} \\
u
\end{array}\right) \mid m\right]=\left(\begin{array}{c}
b_{y^{*}} \sigma_{y^{*}} \\
b_{u} \sigma_{u}
\end{array}\right) m
$$
}

Plugging it into (12), the optimal instrument rule $q=\beta m$ is obtained. 


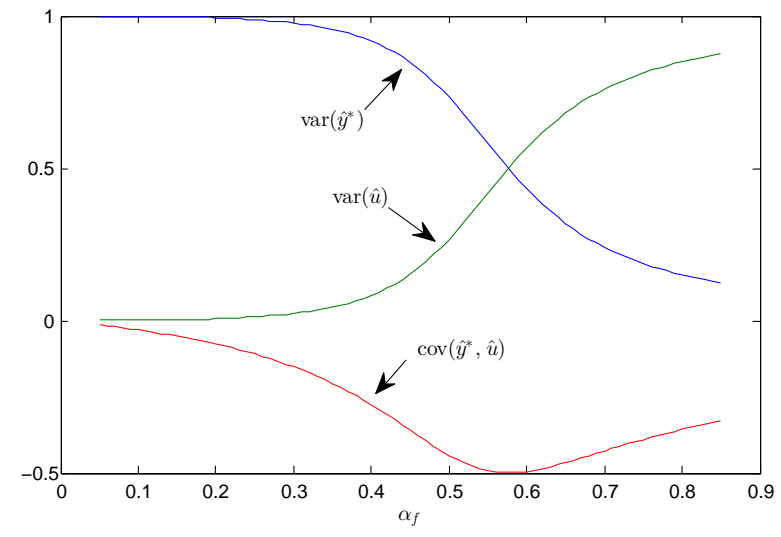

(a) Second moments of the estimates $\left(\alpha_{u}=0.1\right)$

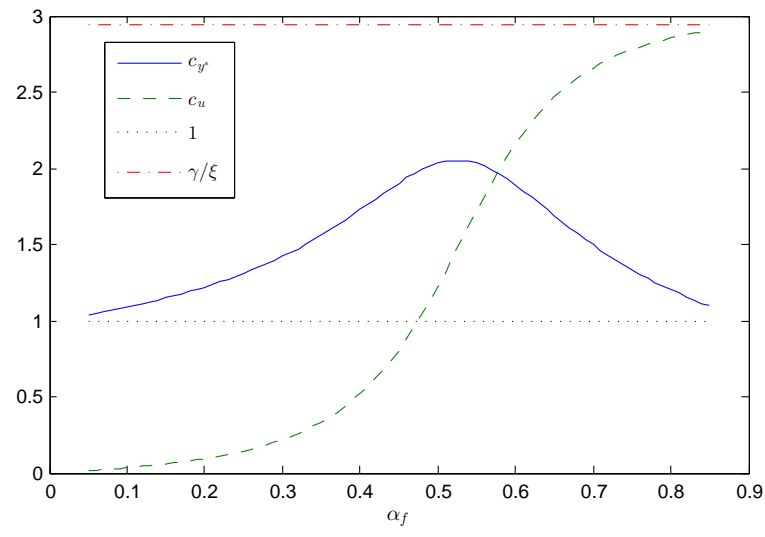

(b) Effective policy responsiveness $\left(\alpha_{u}=0.1\right)$

Figure 1: Properties of optimal policy

It is also worth noting that the optimal policy induces a negative correlation between $\hat{y}$ and $\hat{u} .^{18}$ It may appear detrimental to price stabilization since the volatility of $p_{p}$ and $p_{f}$ expressed in (7) and (8) is lower when $\hat{y}^{*}$ and $\hat{u}$ have a positive correlation. However, the monetary instrument can offset the effects of $\hat{y}$. Then, it becomes important to reduce fluctuations of $\left(p_{f}-p_{p}\right)$ generated by the variability of the residuals. Creating a positive correlation between $\Delta_{y^{*}}$ and $\Delta_{u}$ results in a negative correlation between $\hat{y}^{*}$ and $\hat{u}$. Intuitively, the disclosure rule should be designed to reduce variability of $\left(p_{f}-p_{p}\right)$ that cannot be offset by the monetary instrument.

The optimal instrument rule is essentially described as a linear function of the fundamentals.

$$
q=h\left(g\left(y^{*}, u\right)\right)=c_{y^{*}} y^{*}-c_{u} u
$$

where $c_{y^{*}}=\beta b_{y^{*}} \sigma_{y^{*}}^{-1}$ and $c_{u}=\beta b_{u} \sigma_{u}^{-1}$. By construction, it contains the same information as the optimal policy pair $(g, h)$ reveals.

Corollary 1 An instrument rule $f\left(y^{*}, u\right)=c_{y^{*}} y^{*}-c_{u} u$ with no disclosure $g\left(y^{*}, u\right)=0$ is also optimal.

The coefficients $\left(c_{y^{*}}, c_{u}\right)$ represent the effective responsiveness of the monetary instrument to

\footnotetext{
${ }^{18}$ This argument can be shown as follows. The objective function $\mathbb{E} \Phi\left(\hat{y}^{*}, \hat{u}\right)$ can be written as a linear function of the second moments of the estimates

$$
\mathbb{E} \Phi\left(\hat{y}^{*}, \hat{u}\right)=\frac{1}{2} H_{11} \operatorname{var}\left(\hat{y}^{*}\right)+H_{12} \operatorname{cov}\left(\hat{y}^{*}, \hat{u}\right)+\frac{1}{2} H_{22} \operatorname{var}(\hat{u}) .
$$
}

Since $H_{12}<0$, the central bank prefers a negative covariance between $\hat{y}^{*}$ and $\hat{u}$. 
the fundamentals and are illustrated in Figure 1b. As pointed out by Baeriswyl and Cornand (2010), the central bank distorts its policy response so as to prevent information revelation about the mark-up shock. As $\alpha_{f}$ increases, the monetary instrument should offset the response of the fully informed firms to $u$. However, information revelation about $u$ to the partially informed firms reduces the effectiveness of the monetary channel when $\alpha_{p}$ is high (or $\alpha_{f}$ is low). To reduce the detrimental signaling effects, the optimal instrument rule becomes more responsive to $y^{*}$, thereby changing the informational content of the monetary instrument.

\section{Optimal transparency policy under the inflexible instrument}

The choice of a disclosure rule changes the distribution of market expectations about the fundamentals. As discussed above, the optimality of a negative correlation between $\hat{y}^{*}$ and $\hat{u}$ relies on the fact that the central bank optimally controls its monetary instrument. In other words, it may be optimal to induce a positive correlation between $\hat{y}^{*}$ and $\hat{u}$ when the monetary instrument cannot offset fluctuations of $p_{p}$. To examine this possibility, this section considers the case where the monetary instrument is inflexible and the only means available to the central bank is to control information revelation to the private sector.

Suppose the monetary instrument is inflexible in the sense that nominal demand is fixed as a constant value $q=0$. Then the loss function (denoted by $L_{0}$ ) is given by

$$
\begin{aligned}
L_{0}= & \frac{\alpha_{u}}{\bar{\theta} \xi\left(1-\alpha_{u}\right)+\alpha_{u}}\left(\frac{\left(\bar{\theta} \xi\left(1-\alpha_{u}\right)+\alpha_{u}\right) \hat{y}^{*}-(\bar{\theta}-1) \xi\left(1-\alpha_{u}\right) \xi^{-1} \hat{u}}{\xi\left(1-\alpha_{u}\right)+\alpha_{u}}\right)^{2} \\
& +\frac{\bar{\theta} \xi\left(1-\alpha_{u}\right)}{\bar{\theta} \xi\left(1-\alpha_{u}\right)+\alpha_{u}}\left(\frac{\hat{u}}{\xi}\right)^{2}+\frac{\bar{\theta} \xi \alpha_{f}}{\bar{\theta} \xi \alpha_{f}+1-\alpha_{f}}\left(\frac{\Delta_{u}}{\xi}\right)^{2} \\
& +\frac{1-\alpha_{f}}{\bar{\theta} \xi \alpha_{f}+1-\alpha_{f}}\left(\frac{\left(\bar{\theta} \xi \alpha_{f}+1-\alpha_{f}\right) \Delta_{y^{*}}-(\bar{\theta}-1) \xi \alpha_{f} \xi^{-1} \Delta_{u}}{\xi \alpha_{f}+1-\alpha_{f}}\right)^{2}+t . i . p .
\end{aligned}
$$

where t.i.p. is again the collection of terms whose expected values equal zero under any disclosure rule. The first term in (18) can be interpreted as the value of the monetary channel since that term disappears in (13). As before, the unconditional expected loss is

$$
\mathbb{E} L_{0}=-\mathbb{E} \Phi_{0}\left(\hat{y}^{*}, \hat{u}\right)+\widehat{\text { t.i.p. }}
$$




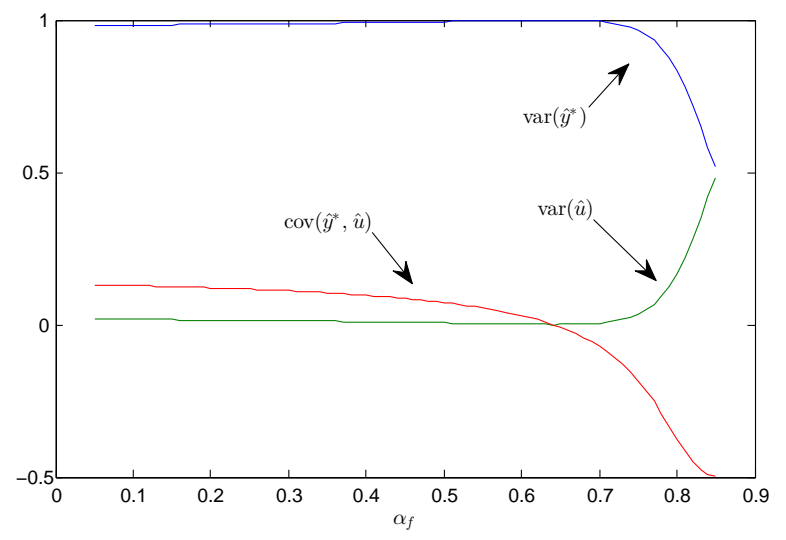

(a) Second moments of the estimates $\left(\alpha_{u}=0.1\right)$

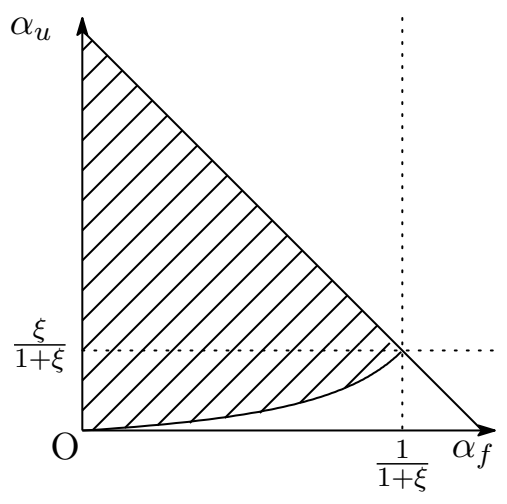

(b) Condition for a positive covariance

Figure 2: Properties of optimal disclosure rule with the inflexible instrument

where $\Phi_{0}$ is a quadratic function defined by

$$
\Phi_{0}\left(\hat{y}^{*}, \hat{u}\right)=\left(\hat{y}^{*}-\frac{\hat{u}}{\xi}\right)\left(d_{y^{*}} \hat{y}^{*}+d_{u} \frac{\hat{u}}{\xi}\right)
$$

and the coefficients are $d_{y^{*}}=(\lambda-\kappa)-(\bar{\theta}-1)[(1-\lambda) \lambda-(1-\kappa) \kappa]$ and $d_{u}=(\lambda-\kappa)+(\bar{\theta}-1)[(1-$ $\lambda) \lambda-(1-\kappa) \kappa]$. It can be shown that if $\lambda=\kappa\left(\right.$ that is, $\left.\alpha_{p}=0\right)$, then $\Phi_{0}\left(\hat{y}^{*}, \hat{u}\right)=0$ for all $\left(\hat{y}^{*}, \hat{u}\right)$. Otherwise, $\Phi_{0}$ is neither concave nor convex (or equivalently, its Hessian matrix $H_{0} \equiv \partial^{2} \Phi_{0} / \partial \hat{y}^{*} \partial \hat{u}$ is indefinite). Hence, the optimal disclosure rule is characterized as follows.

Proposition 3 Suppose that the monetary instrument is inflexible (i.e., $q=0$ ). If $y^{*}$ and $u$ are normally distributed, then the optimal disclosure rule is given by

$$
g_{0}\left(y^{*}, u\right)=\tilde{b}_{y^{*}} \sigma_{y^{*}}^{-1} y^{*}+\tilde{b}_{u} \sigma_{u}^{-1} u
$$

where $\left(\tilde{b}_{y^{*}}, \tilde{b}_{u}\right)$ is the eigenvector associated with the unique positive eigenvalue of $\Sigma^{\frac{1}{2}} H_{0} \Sigma^{\frac{1}{2}}$.

Figure 2a depicts the second moments of the market expectations induced by the optimal disclosure rule under the inflexible policy. Interestingly, $\operatorname{var}(\hat{u})$, which is interpreted as a measure of information revelation about $u$, is U-shaped. That is, as $\alpha_{f}$ increases, the weight on $u$ in (20) decreases from a positive value to a negative value.

The condition under which the optimal disclosure rule induces a positive covariance between $\hat{y}^{*}$ 


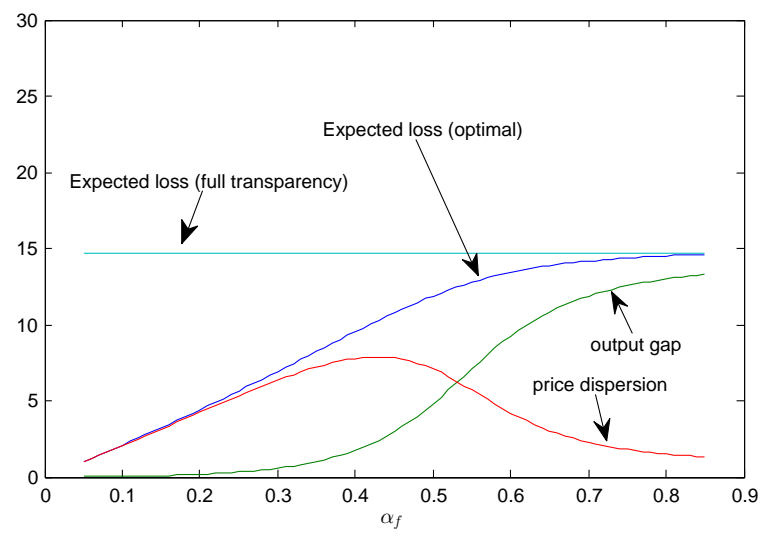

(a) Flexible instrument

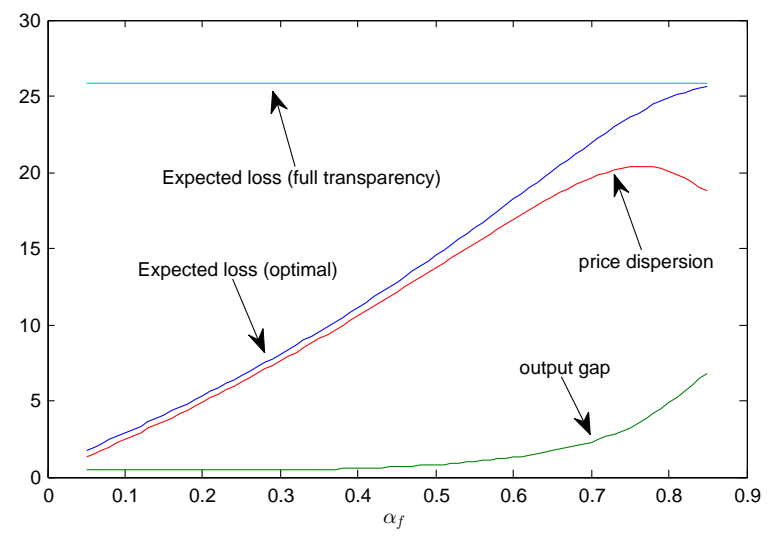

(b) Inflexible instrument

Figure 3: Expected losses under the flexible and inflexible instruments

and $\hat{u}$ is given by $d_{y^{*}}<d_{u}$, or equivalently $\lambda+\kappa<1$. In Figure $2 \mathrm{~b}$, the shaded area represents the set of $\left(\alpha_{f}, \alpha_{u}\right)$ for which this condition holds. Note that $2 \lambda<1$, or equivalently $\alpha_{u}>\xi /(1+\xi)$, is sufficient for this condition. Moreover, it can be shown that $\alpha_{u} \geq \alpha_{f}$ is a sufficient condition for a positive correlation. Conversely, $2 \kappa>1$, or equivalently $\alpha_{f}>1 /(1+\xi)$, is sufficient for a negative correlation. When the fraction of uninformed firms is high, the central bank benefits from reducing volatility of $p_{p}$ rather than $\left(p_{f}-p_{p}\right)$.

Figure 3 compares the expected losses from output gap volatility and from price dispersion under the flexible and inflexible instruments. As $\alpha_{f}$ increases, the output gap volatility monotonically increases while the price dispersion has a single peak. Compared with the expected losses under full transparency, the optimal policy reduces a greater amount of welfare loss when the fraction of partially informed firms is high. Interestingly, compared with the flexible instrument case (the left panel), the optimal disclosure rule with the inflexible instrument may admit a lower output gap volatility.

\section{Concluding remarks}

This paper characterizes the optimal monetary policy and discusses central bank transparency when the economy is subject to two types of shocks and monopolistically competitive firms set their prices under informational frictions. Under the optimal policy, the instrument rule is used to reduce variability of prices of the partially informed firms and the disclosure rule is directed at 
reducing variability of prices of the fully informed firms. Below are some discussions.

- Output stabilization vs. price stabilization:

The central bank has two objectives: to stabilize aggregate output around the efficient level and to reduce price dispersion. To examine the role of stabilization trade-off in optimal policy, two extreme cases are examined where the central bank's objective is either output stabilization or price stabilization.

When the central bank needs to minimize only the output gap volatility, the nominal demand should be chosen to satisfy $q=\hat{y}+\frac{\lambda}{1+\lambda} \frac{\hat{u}}{\xi}$. Given this instrument rule, it is easily shown that full transparency achieves perfect stabilization of the output gap regardless of the informational heterogeneity among firms.

On the other hand, when the central bank minimizes only the price dispersion, it is optimal to choose $q=\hat{y}^{*}-\frac{\hat{u}}{\xi}$. It can also be shown that full disclosure achieves no price dispersion.

In both cases, the monetary instrument can perfectly eliminate the effects of $\hat{y}^{*}$ and $\hat{u}$ simultaneously. Then it makes no sense to withhold information and increase variability of the residuals. In other words, the optimality of partial disclosure comes from the need to accommodate these possibly conflicting objectives.

- Accuracy of the central bank's information:

In the baseline model, the central bank has perfect information about the fundamentals. It can be extended to the case where the central bank has an imperfect signal about the fundamentals. For instance, suppose that the central bank observes a set of signals $\left(s_{1}, \ldots, s_{n}\right)$. When the fundamentals and the signals have a joint normal distribution, the optimal policy pair is analogously characterized as in the perfect information case. That is, it is optimal to disclose a one-dimensional policy index (i.e., a linear combination of the signals), and adjusts nominal demand contingent only on it. Note that the central bank with perfect information can always replicate the optimal policy under the imperfect information case. More generally, it can be shown that the welfare loss under the optimal policy pair is decreasing with the accuracy of the signals. Formally, a set of signals $\mathbf{s}$ is said to be more accurate than $\mathbf{s}^{\prime}$ if the variance-covariance matrix of the conditional expectations 
given $\mathbf{s}$ is greater than that given $\mathbf{s}^{\prime}$ with respect to the Löwner partial ordering. ${ }^{19}$

- Noisy public information with the inflexible instrument:

An important feature of the optimal transparency policy is to induce a correlation, whether positive or negative, between the conditional expectations $\hat{y}^{*}$ and $\hat{u}$. Now consider a disclosure rule that reveals noisy information about each of two shocks: $m=\left(m_{y^{*}}, m_{u}\right)$ such that $m_{y^{*}}=y^{*}+\epsilon_{y^{*}}$ and $m_{u}=u+\epsilon_{u}$. The variance of each noise component, $\operatorname{var}\left(\epsilon_{y^{*}}\right)=\varphi_{y^{*}}$ and $\operatorname{var}(u)=\varphi_{u}$, is controlled by the central bank. Intuitively, the central bank controls how precise each message is. The optimal noisy disclosure rule under the inflexible instrument is given as follows: ${ }^{20}$ if $d_{u} \leq 0$ (or equivalently, $\bar{\theta} /(\bar{\theta}-1) \leq \lambda+\kappa)$, then full disclosure $\left(\varphi_{y^{*}}=\varphi_{u}=0\right)$ is optimal; if $d_{y^{*}}>0>-d_{u}$ (or equivalently, $(\bar{\theta}-2) /(\bar{\theta}-1)<\lambda+\kappa<\bar{\theta} /(\bar{\theta}-1)$ ), then partial disclosure $\left(\varphi_{y^{*}}=0\right.$ and $\varphi_{u}=\infty$ ) is optimal; if $d_{y^{*}} \leq 0$ (or equivalently, $\lambda+\kappa \leq(\bar{\theta}-2) /(\bar{\theta}-1)$ ), then opacity $\left(\varphi_{y^{*}}=\varphi_{u}=\infty\right.$ ) is optimal. Weak strategic complementarities (higher $\xi$ ) and/or weak stickiness of information (lower $\alpha_{u}$ and higher $\alpha_{f}$ ) increase the social value of public information in the present model.

\section{References}

Adam, Klaus. 2007. Optimal Monetary Policy with Imperfect Common Knowledge. Journal of Monetary Economics, 54(2): 267-301.

Angeletos, George-Marios, \& Jennifer La'O. 2012. Optimal Monetary Policy with Informational Frictions. Unpublished Manuscript.

Baeriswyl, Romain, \& Camille Cornand. 2010. The Signaling Role of Policy Actions. Journal of Monetary Economics, 57(6): 682-695.

Blinder, Alan S., Michael Ehrmann, Marcel Fratzscher, Jakob De Haan, \& David-Jan Jansen. 2008. Central Bank Communication and Monetary Policy: A Survey of Theory and Evidence. Journal of Economic Literature, 46(4): 910-945.

Cornand, Camille, \& Frank Heinemann. 2008. Optimal Degree of Public Information Dissemination. Economic Journal, 118: 718-742.

Faust, Jon, \& Lars E. O. Svensson. 2001. Transparency and Credibility: Monetary Policy with Unobserved Goals. International Economic Review, 42(2): 369-397.

Faust, Jon, \& Lars E. O. Svensson. 2002. The Equilibrium Degree of Transparency and Control in Monetary Policy. Journal of Money, Credit and Banking, 34(2): 520-539.

Geraats, Petra M. 2002. Central Bank Transparency. Economic Journal, 112(483): F532-F565.

\footnotetext{
${ }^{19}$ That is, a matrix $A$ is said to be greater than $B$ if $A-B$ is positive semidefinite.

${ }^{20}$ Recall that the objective function can be written as (19).
} 
Hellwig, Christian. 2005. Heterogeneous Information and theWelfare Effects of Public Information Disclosures. Mimeo.

Jensen, Henrik. 2002. Optimal Degree of Transparency in Monetary Policymaking. Scandinavian Journal of Economics, 104(3): 399-422.

Kamenica, Emir, \& Matthew Gentzkow. 2011. Bayesian Persuasion. American Economic Review, 101(6): 2590-2615.

Lorenzoni, Guido. 2010. Optimal Monetary Policy with Uncertain Fundamentals and Dispersed Information. Review of Economic Studies, 77(1): 305-338.

Lucas, Robert E. 1972. Expectations and the Neutrality of Money. Journal of Economic Theory, $4(2): 103-124$.

Mankiw, N. Gregory, \& Ricardo Reis. 2002. Sticky Information Versus Sticky Prices: a Proposal to Replace the New Keynesian Phillips Curve. Quarterly Journal of Economics, 117(4): 1295-1328.

Morris, Stephen, \& Hyun Song Shin. 2002. Social Value of Public Information. American Economic Review, 92(5): 1521-1534.

Morris, Stephen, \& Hyun Song Shin. 2007. Optimal Communication. Journal of the European Economic Association, 5(2-3): 594-602.

Sims, Christopher A. 2003. Implications of Rational Inattention. Journal of Monetary Economics, 50(3): 665-690.

Tamura, Wataru. 2012. A Theory of Multidimensional Information Disclosure. Unpublished Manuscript.

Woodford, Michael. 2005. Central-Bank Communication and Policy Effectiveness. In The Greenspan Era: Lessons for the Future. 399-474. Kansas City:Federal Reserve Bank of Kansas City. 